\title{
DESEMPENHO E PARÂMETROS SANGUÍNEOS DE VACAS LEITEIRAS ALIMENTADAS COM GRÃO DE SOJA\#
}

\author{
BLOOD PARAMETERS AND PERFORMANCE OF DAIRY COWS \\ FED WITH WHOLE RAW SOYBEAN
}

Barletta, R.V. ${ }^{*}$, Rennó, F.P. ${ }^{2}$, Gandra, J.R. ${ }^{1}$, Freitas Júnior, J.É. de ${ }^{1}$, Verdurico, L.C. ${ }^{1}$,
Mingoti, R.D. ${ }^{1}$ e Vilela, F.G. ${ }^{1}$

${ }^{1}$ Faculdade de Medicina Veterinária e Zootecnia. Universidade de São Paulo. FMVZ/USP. Brasil. *barletarafael@usp.br

${ }^{2}$ Departamento de Nutrição e Produção Animal. Faculdade de Medicina Veterinária e Zootecnia. Universidade de São Paulo. FMVZ/USP. francisco.renno@usp.br

\section{PaLAVRAS ChaVE ADICIONAIS}

Ingestão de matéria seca. Leite.

\section{RESUMO}

O objetivo deste estudo foi avaliar os efeitos de diferentes níveis de inclusão de grão de soja cru e integral na alimentação de vacas leiteiras em início de lactação e seus efeitos sobre o consumo de matéria seca, produção e composição do leite e os parâmetros sanguíneos. Foram utilizadas 12 vacas da raça Holandesa, agrupadas em três quadrados latinos balanceados e contemporâneos $4 \times 4$, alimentadas com as seguintes rações: $C$ (controle, sem a inclusão de grão de soja); G8, G16 e G24 com 8,0, 16,0 e 24\% de grão de soja cru e integral na ração, na matéria seca. O consumo de matéria seca, produção de leite e proteína foram menores para os animais submetidos á dieta G24, no entanto os teores de proteína, gordura e lactose não foram influenciados. Não houve efeito das rações fornecidas para as vacas sobre as concentrações dos parâmetros sanguíneos analisados, exceto para as variáveis colesterol total e colesterol-HDL.

\section{SUMMARY}

The aim of this study was to evaluate the effects of different levels of inclusion of crude whole soy bean in feeding of dairy cows in early lactation and its effects on dry matter intake, milk yield and composition and blood parameters. A

"Parte da Dissertação de Mestrado do primeiro autor.
AdDitiOnAL KEYWORDS

DM intake. Milk.

total of 12 Holstein cows, grouped in three Latin square contemporary balanced $4 \times 4$, fed with the following diets: C (control without soybean; G8, G16 and G24 with 8, 16 and $24 \%$ of crude whole soybean in dry matter. The dry matter intake and milk yield were lower for animals fed diet G24; crude protein, fat and lactose contents were not influenced. There was no effect on of blood parameters concentrations except for total cholesterol and HDL-cholesterol.

\section{INTRODUÇÃO}

Entre as diferentes fontes de proteína e gordura disponíveis para serem utilizadas na alimentação de ruminantes no Brasil, o grão de soja se destaca pela grande disponibilidade e custo compatível com seu rico conteúdo de nutrientes. Atualmente segundo dados do Agrianual (2009), o Brasil é o segundo produtor mundial de soja, com 68,5 milhões de toneladas produzidas na safra 2009/2010.

Além disto, se forem analisadas as regiões do país onde a soja é cultivada, existe expressiva cultura de soja, em regiões onde estão localizadas as maiores bacias leiteiras do Brasil, tornando sua utilização 
na alimentação animal possível nas principais regiões produtoras de leite do país (Rennó et al., 2009).

Por apresentar composição de aproximadamente $39,3 \%$ de proteína bruta, $19,2 \%$ de extrato etéreo e $95 \%$ de NDT, o grão de soja tem sido utilizado na alimentação de ruminantes com o propósito de ser fonte de proteína, e por também apresentar uma fibra de alta digestibilidade, e com efetividade mediana (NRC, 2001; Valadares Filho et al., 2006). Também, pelo elevado teor de extrato etéreo, pode ser considerado alimento fonte de gordura para ruminantes.

A utilização de fontes de gordura nas rações de vacas leiteiras é feita durante a lactação por aumentar a densidade energética da ração sem reduzir o conteúdo de fibras e, assim, aumentar a ingestão de energia e produção de leite. Entre as vantagens de utilização de grão de soja integral como fonte de gordura pode ser citada a lenta liberação de lipídeos no rúmen, impedindo possível perda da digestibilidade da fibra pelo efeito negativo que gorduras insaturadas prontamente disponíveis no rúmen podem causar as bactérias fibrolíticas (Palmquist, 1991).

No entanto, a utilização de grão de soja integral cru na alimentação de ruminantes tem sido evitada devido à possível presença de substâncias tóxicas e também, devido à possível presença de fatores que inibam a atividade da tripsina ou quimiotripsina. A presença destes fatores poderia apresentar um potencial de reduzir a digestibilidade da proteína da dieta e aumentar a excreção de nitrogênio (McDonald et al., 2002).

Para o estudo de avaliação de alimentos na nutrição animal, tem sido empregado o estudo dos perfis metabólicos, e adicionalmente são estudados metabólitos indicadores do funcionamento hepático como as enzimas aspartato amino transferase, gama gutamil tranferase e fosfatase alcalina (Gonzalez, 1997).

O objetivo deste estudo foi avaliar o desempenho produtivo e os parâmetros san- guíneos de vacas leiteiras alimentadas com grão de soja cru e integral.

\section{MATERIALE MÉTODOS}

O experimento foi conduzido nas dependências do Laboratório de Pesquisa em Bovinos de Leite da Faculdade de Medicina Veterinária e Zootecnia da Universidade de São Paulo, Campus de Pirassununga, no período de 20 de maio a 11 de agosto de 2009. Foram utilizadas 12 vacas da raça Holandesa, agrupadas em três quadrados latinos $4 \times 4$, contemporâneos e balanceados de acordo com o período de lactação. O experimento foi constituído por quatro períodos, com duração de 21 dias cada um, sendo os 14 primeiros dias de adaptação às rações e os demais para avaliar as variáveis mensuradas. Os animais foram alimentados com quatro rações experimentais, formuladas para serem isonitrogenadas, de forma a atenderem as exigências nutricionais de vacas em lactação com aproximadamente $580 \mathrm{~kg}$ de peso corporal, 12 semanas de lactação, produzindo diariamente $30 \mathrm{~kg}$ de leite com $3,5 \%$ de gordura, conforme recomendações do NRC (2001).

Os animais foram distribuídos aleatoriamente para receber as seguintes rações experimentais: 1) Controle (C), composto por ração sem a inclusão de grão de soja; 2) Grão de soja integral 8\% (G8); 3) Grão de soja integral 16\% (G16), e 4) Grão de soja integral $24 \%(\mathrm{G} 24)$, com a utilização respectivamente, de 8,0,16,0 e 24\% de grão de soja cru e integral na ração, na matéria seca, sendo a relação volumoso: concentrado de 50:50 e o concentrado na forma farelada. Durante o período experimental foi utilizada a silagem de milho como volumoso, e as respectivas rações e água foram fornecidos ad libitum.

Diariamente foram feitas pesagens das quantidades dos volumosos e concentrados fornecidos e das sobras de cada tratamento, para estimativa do consumo. Os animais foram arraçoados de acordo com o 


\section{VACAS LEITEIRAS ALIMENTADAS COM GRÃO DE SOJA CRU E INTEGRAL}

consumo de matéria seca no dia anterior, de forma a ser mantido um percentual de sobras das rações, diariamente, entre 5 e $10 \%$ do fornecido para não haver limitação de consumo. Após o preparo da mistura no cocho, as amostras dos alimentos e sobras foram coletadas e armazenadas a $-20^{\circ} \mathrm{C}$. Posteriormente foram realizadas análises químico-bromatológicas nas amostras armazenadas. As coletas das amostras foram realizadas ao final de cada período experimental, após o período de adaptação as rações.

Nas amostras de sobras e alimentos fornecidos foram determinados os teores de matéria seca (MS), matéria orgânica, cinzas, extrato etéreo, o nitrogênio insolúvel em detergente neutro, nitrogênio insolúvel em detergente ácido e lignina de acordo com as metodologias descritas por AOAC (2000). $\mathrm{O}$ teor de proteína bruta foi obtido pela multiplicação do teor de nitrogênio total por 6,25 . Os teores de fibra detergente neutro e fibra detergente ácido foram obtidos conforme método descrito por Van Soest et al. (1991), utilizando-se $\alpha$-amilase e sem adição de sulfito de sódio na determinação do FDN.

Os teores de carboidratos totais (CT) foram calculados segundo Sniffen et al. (1992):

$C T=100-(\%$ PB $+\% E E+\%$ Cinzas $)$

Carboidratos não-fibrosos (CNF), de acordo com Hall (1998):

$\mathrm{CNF}=100-[(\% \mathrm{~PB}-\% \mathrm{~PB}$ uréia $+\%$ uréia $)+$ $\% \mathrm{EE}+\% \mathrm{MM}+\% \mathrm{FDN}]$

Nutrientes digestíveis totais (NDT), segundo Weiss (1992):

$\mathrm{NDT}(\%)=\mathrm{PBD}+\mathrm{FDND}+\mathrm{CNFD}+(\mathrm{EED} \times 2,25)$

em que:

$\mathrm{PBD}=$ proteína bruta digestível;

FDND= fibra em detergente neutro digestível; $\mathrm{CNFD}=$ carboidratos não-fibrosos digestíveis; $\mathrm{EED}=$ extrato etéreo digestível.
Energia líquida de lactação (ELL), segundo o NRC (2001):

$\operatorname{ELL}($ Mcal $/ \mathrm{kg})=[0,703 X$ Energia metabolizável (Mcal/kg)] - 0,19

sendo os valores de PBD, FDND, CNFD e EED obtidos através dos coeficientes de digestibilidade de cada nutriente em questão.

As vacas foram ordenhadas mecanicamente duas vezes ao dia, as 6:30 e as 15:30 horas, sendo a produção de leite registrada diariamente durante todo o período experimental. A produção de leite foi corrigida para 3,5\% de gordura (PLC) segundo fórmula de Sklan et al. (1992):

$\mathrm{PLC}=(0,432+0,1625$ * teor de gordura do leite $)$ * $\mathrm{kg}$ de leite

Foi determinado o teor de gordura e proteína do leite, sendo a proteína analisada pelo método de gerber e a proteina pelo método de kjeldahl, usando o fator de 6,38 no cálculo (AOAC, 2000).

Para determinação da uréia e nitrogênio uréico no leite (NUL), as amostras de leite foram desproteinizadas. As análises da concentração de uréia no leite desproteinizado foram realizadas no Laboratório de Bioquímica e Fisiologia Animal do Departamento de Nutrição e Produção Animal da FMVZ-USP, por meio de kits comerciais (Laborlab® e CELM ${ }^{\circledR}$ ). A concentração de NUL foi determinada indiretamente por meio da seguinte fórmula:

$$
\mathrm{NUL}=\text { uréia }(\mathrm{mg} / \mathrm{dL}) / 2,14
$$

Nas tabelas I e II estão descritas as proporções dos ingredientes do concentrado e a composição percentual e químicabromatológica das rações experimentais. Foi avaliado o consumo de matéria seca, matéria orgânica, proteína bruta, fibra em detergente neutro, extrato etéreo, carboidratos totais e não-fibrosos, consumo de NDT e energia líquida. 
As coletas de sangue foram realizadas no $19^{\circ}$ dia de cada período experimental por punção da veia e/ou artéria coccígea, anteriormente ao fornecimento das rações no período da manhã. As amostras foram coletadas em tubos vacuolizados (vacutainer) de $10 \mathrm{~mL}$ para dosagem dos parâmetros sanguíneos glicose, colesterol total, colesterol-HDL, proteínas totais, albumina, uréia e nitrogênio uréico, as enzimas aspartatoaminotransferase (AST) gama glutamiltransferase (GTA) e fosfatase alcalina (FA), no soro, e tubos contendo fluoreto de sódio para dosagem de glicose no plasma.

Imediatamente após coleta as amostras foram coletadas refrigeradas e centrifugadas a 2000 x g durante 15 minutos, para a separação do soro ou plasma. O centrifugado obtido foi transferido para tubetes plásticos, identificados e armazenados a $-20^{\circ} \mathrm{C}$, até o procedimento das análises laboratoriais, onde foram analisados e expressos a $30^{\circ} \mathrm{C}$.

As análises das concentrações dos parâmetros sanguíneos foram realizadas no Laboratório de Bioquímica e Fisiologia Animal do Departamento de Nutrição e Produção Animal da FMVZ-USP, por meio de kits comerciais (Laborlab® e CELM®) que utilizam método enzimático colorimétrico de ponto final, sendo a leitura realizada em analisador automático de bioquímica sanguínea (Sistema de Bioquímica Automático SBA-200CELM®).

Os dados obtidos foram submetidos ao SAS (2004), verificando a normalidade dos resíduos e a homogeneidade das variâncias pelo PROC UNIVARIATE.

Os dados foram analisados, pelo PROC MIXED de acordo com a seguinte modelo:

$$
Y_{i j k y}=\mu+Q_{i}+A_{j}+P_{y}+T_{k}+e_{i j y k}
$$

onde:

$\mathrm{Y}_{\mathrm{ijyk}}=$ variável dependente,

$\mu=$ media geral,

$\mathrm{Q}_{\mathrm{i}}=$ efeito de quadrado $(\mathrm{i}=1$ to 3$)$,
Tabela I. Proporção dos ingredientes do concentrado, expressa na matéria seca $(\% M S)$. (Proportion of the ingredients of the concentrate, expressed on dry matter (\% DM)).

\begin{tabular}{lcccc}
\hline & C & G8 & G16 & G24 \\
\hline Milho moído & 54,41 & 45,74 & 40,18 & 34,52 \\
Farelo de soja & 37,76 & 31,09 & 21,07 & 10,14 \\
Grão de soja & - & 16,07 & 32,13 & 48,75 \\
Uréia & 1,04 & 0,38 & - & - \\
Sulfato de amônia & 0,20 & 0,20 & 0,10 & - \\
Bicarbonato de sódio & 1,60 & 1,60 & 1,61 & 1,62 \\
Óxido de magnésio & 0,18 & 0,18 & 0,18 & 0,18 \\
Calcáreo & 0,28 & 0,28 & 0,28 & 0,28 \\
Premix & 3,97 & 3,97 & 3,97 & 4,02 \\
Sal comum & 0,48 & 0,48 & 0,48 & 0,49
\end{tabular}

C, G8, G16 e G24: 0, 8, 16 e 24 \%MS respectivamente de grão de soja cru integral na ração.

${ }^{1}$ Composição/kg: cálcio-190 g, fósforo-73 g, enxofre-30 g, magnésio- $44 \mathrm{~g}$, cobre- $340 \mathrm{mg}$, zinco$1350 \mathrm{mg}$, manganês- $940 \mathrm{mg}$, cobalto- $3 \mathrm{mg}$, iodo$16 \mathrm{mg}$, selênio-10 mg, ferro-1064 mg, vitamina A100 000, vitamina D-40 000, vitamina E-600,0.

$A_{i}=$ efeito de animal $(j=1$ to 12$)$,

$P_{y}=$ efeito do período $(y=1$ to 4$)$,

$\mathrm{T}_{\mathrm{k}}^{\mathrm{y}}=$ efeito do tratamento ( $\mathrm{k}=1$ to 4$)$,

$\mathrm{e}_{\mathrm{ijk}}=$ erro.

Efeito aleatório $A_{i}\left(Q_{i}\right)=$ interação animal quadrado.

Os graus de liberdade calculados foram realizados de acordo com o método satterthwaite (ddfm $=$ satterth).

Os dados obtidos foram submetidos à análise de variância e regressão polinomial pelo comando PROC MIXED do SAS, versão 9.0 (SAS, 2004), adotando-se nível de significância de 5\%. As médias foram ajustadas pelo LSMEANS e analisadas pelo teste de Tukey ajustado do PROC MIXED.

\section{RESULTADOSEDISCUSSÃO}

Em relação ao consumo de matéria seca observou-se efeito linear decrescente $(\mathrm{p}<0,05)$ no consumo de matéria seca, de forma que os animais submetidos à ração contendo $24 \%$ de grão de soja apresentaram 


\section{VACAS LEITEIRAS ALIMENTADAS COM GRÃO DE SOJA CRU E INTEGRAL}

Tabela II. Composição bromatológica das rações experimentais. (Chemical composition of experimental diets).

\begin{tabular}{|c|c|c|c|c|}
\hline & \multicolumn{4}{|c|}{ Rações experimentais } \\
\hline & C & G8 & G16 & G24 \\
\hline \multicolumn{5}{|l|}{ Ingredientes (\%) } \\
\hline Silagem de milho & 50,17 & 50,17 & 50,17 & 50,17 \\
\hline Milho moído & 27,10 & 22,80 & 20,02 & 17,02 \\
\hline Farelo de soja & 18,83 & 15,50 & 10,50 & 5,00 \\
\hline Grão de soja & - & 8,01 & 16,01 & 24,04 \\
\hline Uréia & 0,52 & 0,19 & - & - \\
\hline Sulfato de amônia & 0,10 & 0,10 & 0,05 & - \\
\hline Bicarbonato de sódio & 0,80 & 0,80 & 0,80 & 0,80 \\
\hline Óxido de magnésio & 0,09 & 0,09 & 0,09 & 0,09 \\
\hline Calcáreo & 0,14 & 0,14 & 0,14 & 0,14 \\
\hline Agromix leite ${ }^{1}$ & 1,98 & 1,98 & 1,98 & 1,98 \\
\hline Sal comum & 0,24 & 0,24 & 0,24 & 0,24 \\
\hline \multicolumn{5}{|l|}{ Composição química } \\
\hline Matéria seca $(\mathrm{MS})^{2}$ & 62,01 & 62,13 & 62,27 & 61,98 \\
\hline Matéria orgânica $(\mathrm{MO})^{3}$ & 91,92 & 92,12 & 92,28 & 92,28 \\
\hline Matéria mineral $(\mathrm{MM})^{3}$ & 8,08 & 7,88 & 7,72 & 7,72 \\
\hline Proteína bruta $(\mathrm{PB})^{3}$ & 16,97 & 16,96 & 16,66 & 16,64 \\
\hline Nitrogênio insolúvel em detergente neutro (NIDN) ${ }^{4}$ & 20,51 & 20,43 & 20,43 & 20,43 \\
\hline Nitrogênio insolúvel em detergente ácido (NIDA) ${ }^{4}$ & 12,05 & 11,81 & 11,31 & 10,65 \\
\hline Extrato etéreo $(\mathrm{EE})^{3}$ & 3,02 & 4,46 & 5,9 & 7,26 \\
\hline Carboidratos totais $(\mathrm{CT})^{3}$ & 71,93 & 70,70 & 69,72 & 68,37 \\
\hline Fibra em detergente neutro (FDN) ${ }^{3}$ & 33,04 & 33,48 & 33,91 & 32,83 \\
\hline FDN corrigida para cinzas e proteína $\left(\mathrm{FDN}_{\mathrm{CP}}\right)^{3}$ & 28,90 & 29,19 & 29,58 & 28,41 \\
\hline Carboidratos não fibrosos $(\mathrm{CNF})^{3}$ & 42,14 & 40,33 & 38,99 & 38,74 \\
\hline Fibra em detergente ácido $(\mathrm{FDA})^{3}$ & 21,26 & 21,88 & 22,4 & 22,24 \\
\hline Lignina $^{3}$ & 3,80 & 4,0 & 4,12 & 4,25 \\
\hline Nutrientes digestíveis totais $(\mathrm{NDT})^{5}$ & 73,31 & 74,08 & 75,42 & 76,95 \\
\hline Energia líquida de lactação $\left(\mathrm{EL}_{L}\right)^{5}(\mathrm{Mcal} / \mathrm{kg})$ & 1,72 & 1,75 & 1,79 & 1,84 \\
\hline
\end{tabular}

${ }^{1}$ Composição por quilograma de produto: cálcio-190 g, fósforo-73 g, enxofre-30 g, magnésio-44 g, cobre- $340 \mathrm{mg}$, zinco-1350 mg, manganês- $940 \mathrm{mg}$, cobalto- $3 \mathrm{mg}$, iodo- $16 \mathrm{mg}$, selênio-10 mg, ferro-1064 $\mathrm{mg}$, vitamina A-100000, vitamina D-40000, vitamina E-600,0; ${ }^{2}$ Valor expresso em porcentagem da matéria natural; ${ }^{3}$ Valores expressos em porcentagem da matéria seca; ${ }^{4}$ Valores expressos em porcentagem do nitrogênio total; ${ }^{5}$ Valores estimados pelas equações do NRC (2001);

C, G8, G16 e G24: 0, 8, 16 e 24 \%MS respectivamente de grão de soja cru integral na ração.

menor consumo de matéria seca entre as rações experimentais, e os animais submetidos às dietas C e G8 e G16 não diferiram entre si (tabela III). Possivelmente essa redução pode ser justificada em parte pela aceitabilidade da dieta G24 e pelos altos teores de extrato etéreo nas mesmas, pois o consumo de grão de soja dos animais submetidos à dieta $\mathrm{G} 24$ chegou a atingir 6 a $7 \mathrm{~kg} / \mathrm{vaca} / \mathrm{dia}$, e esta dieta possuía na sua composição química-bromatológica 7,26\% extrato etéreo.

Allen (2000) avaliou vários experimentos que utilizaram rações contendo diferen- 
tes fontes de gordura para vacas em lactação, e observou que rações contendo sais de cálcio de ácidos graxos apresentaram maior redução no consumo em relação a outras fontes de gordura, como óleos, sementes de oleaginosas e gordura animal.

Quando são avaliadas diferentes fontes de gordura nas rações de vacas leiteiras, diferentes respostas são esperadas estando relacionadas ao tipo e nível de inclusão do suplemento de gordura na ração. Para rações contendo de 5 a $6 \%$ de extrato etéreo na matéria seca, segundo o NRC (2001), a adição de óleo de sementes e ácidos graxos parcialmente hidrogenados reduz o consumo, entretanto quando se utiliza semente de oleaginosas como o grão de soja, esta redução no consumo pode não ser observada.

De forma semelhante Bernard (1990) não encontrou diferença significativa no consumo de MS quando comparou o grão de soja cru com o tostado e com farelo de soja, incluídos em 9,4\% na matéria seca da ração, juntamente com silagem de milho, em uma relação V/C de 50:50, com vacas em início de lactação com produção média de $32 \mathrm{~kg} / \mathrm{leite} /$ dia, com um consumo médio de matéria seca de $21,4 \mathrm{~kg} / \mathrm{dia}$, resultados próximos aos deste experimento.

Deresz et al. (1996), utilizaram vacas em início de lactação e com média de produção de leite de $28,0 \mathrm{~kg} /$ dia, incluíram 0, 12 e $24 \%$ de grão de soja cru na matéria seca da dieta, e utilizaram silagem de milho como volumoso em uma relação V/C de 60:40, os autores não encontraram diferença no consumo de MS entre as dietas experimentais, e os resultados são próximos dos encontrados neste estudo.

Houve efeito linear decrescente $(\mathrm{p}<0,05)$ sobre a produção de leite (tabela III), onde, os animais que receberam a ração G24 apresentaram menor produção de leite quando comparada as demais rações utilizadas, não sendo observadas diferenças na produção de leite nos animais submetidos às dietas controle, G8 e G16. Este resultado pode ser explicado pelo menor consumo de matéria seca, dos animais submetidos à die- ta G24. Também houve efeito das dietas experimentais $(\mathrm{p}<0,05)$ sobre a produção de proteína no leite, sendo que os animais submetidos às dietas G16e G24 apresentaram valores inferiores aos animais submetidos às dietas controle e G8. Estes resultados podem ser explicados por alterações na fermentação ruminal, ou pelo menor substrato para os microorganismos ruminais provenientes das dietas com maiores teores de extrato etéreo, que podem levar a redução na síntese de proteína microbiana, conseqüentemente, na quantidade de proteína microbiana absorvida e que chegaria à glândula mamária, influenciando negativamente a produção de proteína no leite. Além disso, os animais submetidos à dieta G24 tiveram menor consumo de matéria seca e conseqüentemente menor produção de leite.

A ingestão de energia pode ser aumentada pela inclusão de gordura nas dietas, contrariamente ao aumento da energia disponível através do aumento na ingestão de matéria seca, da maior de concentrados ou carboidratos não estruturais, ou até mesmo da melhor utilização do amido disponível, a adição de gordura na dieta normalmente diminui a porcentagem de proteína no leite em 0,1 a 0,3 unidades percentuais, como pôde ser visto no experimento. A explicação para isto é que os microorganismos ruminais não são capazes de utilizar os lipídeos como fonte de energia para o seu crescimento (Palmquist, 1991).

Não houve efeito $(p>0,05)$ das rações experimentais sobre a produção de leite corrigido, teor e produção de gordura e lactose, teor de proteína, uréia e nitrogênio uréico no leite (tabela III). Esse resultado indica que possivelmente o aporte de nutrientes para o animal e especialmente para a glândula mamária não foi limitado pelos níveis de grão de soja nas rações experimentais, e que provavelmente a inclusão de grão de soja na matéria seca total de 8 a $16 \%$ não influenciou a digestibilidade da matéria seca. Entretanto, como os animais da dieta G24 tiveram menor 


\section{VACAS LEITEIRAS ALIMENTADAS COM GRÃO DE SOJA CRU E INTEGRAL}

Tabela III. Consumo, desempenho produtivo e composição do leite em função das rações experimentais. (Intake, productive performance and milk composition according to the experimental diets).

\begin{tabular}{|c|c|c|c|c|c|c|c|c|}
\hline & \multicolumn{4}{|c|}{ Rações experimentais } & \multirow[b]{2}{*}{ Média } & \multirow[b]{2}{*}{ EPM } & \multicolumn{2}{|c|}{$\mathrm{p}$} \\
\hline & C & G8 & G16 & G24 & & & L & Q \\
\hline \multicolumn{9}{|l|}{$\mathrm{kg} / \mathrm{dia}$} \\
\hline Consumo MS & $25,30^{a}$ & $24,93^{\mathrm{ab}}$ & $24,75^{\mathrm{ab}}$ & $23,84^{b}$ & 24,71 & 0,57 & 0,001 & 0,356 \\
\hline Produção de leite & $32,20^{a}$ & $31,58^{\mathrm{ab}}$ & $31,05^{\mathrm{ab}}$ & $30,01^{b}$ & 31,21 & 0,56 & 0,006 & 0,688 \\
\hline Produção corrigida & 29,46 & 29,09 & 30,33 & 28,14 & 29,26 & 0,78 & 0,472 & 0,282 \\
\hline Gordura & 0,95 & 0,96 & 1,04 & 0,94 & 0,97 & 0,04 & 0,776 & 0,244 \\
\hline Proteína & $0,96^{a}$ & $0,92^{\mathrm{ab}}$ & $0,83^{b}$ & $0,84^{b}$ & 0,89 & 0,02 & 0,001 & 0,297 \\
\hline Lactose & 1,25 & 1,23 & 1,20 & 1,18 & 1,22 & 0,03 & 0,281 & 0,920 \\
\hline \multicolumn{9}{|l|}{ Porcentagem } \\
\hline Gordura & 2,96 & 3,00 & 3,30 & 3,06 & 3,08 & 0,10 & 0,318 & 0,279 \\
\hline Proteína & 2,98 & 2,93 & 2,70 & 2,86 & 2,87 & 0,05 & 0,146 & 0,221 \\
\hline Lactose & 4,23 & 4,28 & 4,00 & 4,25 & 4,19 & 0,05 & 0,685 & 0,352 \\
\hline \multicolumn{9}{|l|}{$\mathrm{mg} / \mathrm{dL}$} \\
\hline Uréia no leite & 35,71 & 32,91 & 30,02 & 30,17 & 32,58 & 0,40 & 0,227 & 0,106 \\
\hline NUL & 16,69 & 14,76 & 13,46 & 13,53 & 14,61 & 0,19 & 0,227 & 0,106 \\
\hline Peso corporal (kg) & 554,70 & 554,70 & 554,18 & 554,54 & 554,53 & 5,74 & 0,896 & 0,916 \\
\hline ECC & 2,50 & 2,49 & 2,44 & 2,50 & 2,48 & 0,02 & 0,465 & 0,258 \\
\hline Eficiência $^{1}$ & 1,28 & 1,27 & 1,26 & 1,27 & 1,27 & 0,02 & 0,364 & 0,439 \\
\hline
\end{tabular}

C, G8, G16 e G24: 0, 8, 16 e 24 \%MS respectivamente de grão de soja cru integral na ração; p: Probabilidades de resposta linear (L), ou quadrática (Q); ECC: Escore de condição corporal; NUL: Nitrogenio ureico no leite.

abMédias seguidas de letras diferentes nas linhas se diferem em $5 \%$ no Teste de Tukey ajustado pelo Proc Mixed.

${ }^{1} \mathrm{~kg}$ de leite/kg de matéria seca consumida.

consumo de matéria seca, este refletiu na menor produção de leite, vista no presente estudo. A concentração de nitrogênio no leite em forma de uréia esta positivamente correlacionada com a concentração de uréia sanguínea, ambas utilizadas como indicadores da correta utilização da proteína dietética Gandra et al. (2009).

Não houve efeito $(p>0,05)$ das rações experimentais sobre a eficiência produtiva (tabela III), entretanto os animais submetidos à dieta G24 tiveram menor consumo de matéria seca e produção de leite que os animais submetidos às dietas controle, G8 e G16. Por este motivo não foi observada diferença na eficiência produtiva, mas os animais que receberam esta dieta tiveram desempenho produtivo inferior às demais.

Wu e Hurber (1993) revisaram dados de 49 experimentos envolvendo 83 comparações entre rações com e sem adição de gordura em vacas leiteiras, e observaram que na maioria dos casos o teor de proteína foi reduzido pela adição de fontes de gordura nas rações, sendo o grau de depressão dependente da fonte de gordura.

Não houve diferença $(p>0,05)$ entre as rações experimentais para as concentrações no soro de glicose, uréia, nitrogênio uréico, proteínas totais, albumina, gama glutamiltransferase (GGT) e fosfatase alcalina (FA) (tabela IV). 
Foi observado efeito linear crescente $(\mathrm{p}<0,05)$ para as concentrações de colesterol total e colesterol HDL (tabela IV). Quando foram comparadas as médias, para concentração de colesterol total, foi observado maior valor para a ração $\mathrm{G} 24$ em relação às demais, entretanto não houve diferença entre as rações G8 e G16 (tabela IV). Foi observado aumento de 1,32 vezes quando comparou a dieta $\mathrm{G} 24$ com o controle, para as concentrações de colesterol total. Este aumento da concentração do colesterol HDL no lipidograma do soro pode ser justificado devido ao maior consumo de ácidos graxos nas rações, que proporcionou aumento das respectivas frações relativas ao metabolismo de lipídios transportadas no sangue.

Nas concentrações de AST foi observado efeito linear crescente $(\mathrm{p}<0,05)$, porém não foi observado diferença entre as dietas experimentais (tabela IV). Além disso, os valores obtidos estão dentro da variação normal encontrada para vacas em lactação (Kaneko et al., 1997).

Elliott et al.(1993), de forma semelhante, observaram aumento da concentração de colesterol total no sangue de vacas com cerca de 64 dias em lactação e suplementadas com diferentes fontes de gordura, com médias de $217 \mathrm{mg} / \mathrm{dL}$ e $246 \mathrm{mg} / \mathrm{dL}$, respectivamente, para os níveis de 2,5 e 5,0 \% de EE na dieta. De acordo com Schauff et al. (1992) e Elliott et al. (1993), este aumento da concentração de colesterol total no sangue ocorre devido à elevação da demanda necessária para digestão, absorção e transporte de ácidos graxos de cadeia longa ingerida advinda das fontes de gordura.

Bremmer et al. (1998) também observaram aumento da concentração de colesterol total em vacas que receberam infusão de misturas de ácidos graxos de cadeia longa

Tabela IV. Metabólitos plasmáticos em função das rações experimentais. (Plasma metabolites according to the experimental diets).

\begin{tabular}{|c|c|c|c|c|c|c|c|c|}
\hline & \multicolumn{4}{|c|}{ Rações experimentais } & \multirow[b]{2}{*}{ Média } & \multirow[b]{2}{*}{ EPM } & \multicolumn{2}{|c|}{ r } \\
\hline & C & G8 & G16 & G24 & & & L & Q \\
\hline \multicolumn{9}{|l|}{$\mathrm{mg} / \mathrm{dL}$} \\
\hline Glicose & 63,53 & 66,53 & 62,53 & 65,69 & 64,57 & 2,00 & 0,796 & 0,562 \\
\hline Colesterol & $190,61^{\mathrm{b}}$ & $212,84^{\mathrm{ab}}$ & $241,76^{a}$ & $251,84^{a}$ & 224,26 & 6,15 & 0,014 & 0,363 \\
\hline C-HDL & $117,30^{\mathrm{b}}$ & $128,30^{\mathrm{ab}}$ & $144,15^{\mathrm{a}}$ & $143,15^{\mathrm{a}}$ & 133,23 & 3,82 & 0,007 & 0,050 \\
\hline Uréia & 38,61 & 39,92 & 41,00 & 38,92 & 39,61 & 1,53 & 0,481 & 0,778 \\
\hline NUS & 18,04 & 18,65 & 19,16 & 18,18 & 18,51 & 0,71 & 0,481 & 0,778 \\
\hline \multicolumn{9}{|l|}{$\mathrm{g} / \mathrm{L}$} \\
\hline Proteínas totais & 4,93 & 5,29 & 5,14 & 5,22 & 5,14 & 0,12 & 0,125 & 0,366 \\
\hline Albumina & 2,41 & 2,38 & 2,36 & 2,44 & 2,40 & 0,03 & 0,931 & 0,878 \\
\hline \multicolumn{9}{|l|}{$\mathrm{U} / \mathrm{L}$} \\
\hline AST & 60,92 & 62,38 & 64,07 & 67,00 & 63,59 & 1,58 & 0,028 & 0,189 \\
\hline GGT & 4,30 & 4,64 & 4,23 & 4,64 & 4,45 & 0,14 & 0,239 & 0,340 \\
\hline FA & 35,30 & 35,76 & 36,53 & 38,15 & 36,44 & 1,29 & 0,171 & 0,166 \\
\hline
\end{tabular}

C, G8, G16 e G24: 0, 8, 16 e 24 \%MS respectivamente de grão de soja cru integral na ração; $p$ : Probabilidades de resposta linear (L), ou quadrática (Q); C-HDL: Colesterol-lipoproteína de alta densidade; NUS: Nitrogênio uréico no soro; AST: Aspartato aminotransferase; GGT: Gamma glutamil transferase; FA: Fosfatase alcalina.

abMédias seguidas de letras diferentes nas linhas se diferem em $5 \%$ no Teste de Tukey ajustado pelo Proc Mixed.

Archivos de zootecnia vol. 61, núm. 236, p. 490. 


\section{VACAS LEITEIRAS ALIMENTADAS COM GRÃO DE SOJA CRU E INTEGRAL}

no abomaso, de forma semelhante a Christensen et al. (1994), que verificaram tendência de aumento da concentração de triglicerídeos em vacas que receberam misturas de ácidos graxos de cadeia longa no abomaso.

A concentração de glicose plasmática não foi influenciada pelas rações experimentais, sendo este resultado semelhante aos estudos de Drackley et al. (1992); Elliott et al. (1993) e Bremmer et al. (1998), que verificaram concentração semelhante de glicose plasmática em vacas suplementadas com diferentes fontes de gordura. A manutenção da concentração de glicose plasmática se relaciona à relativa estabilidade nas concentrações de glicose em ruminantes.

Oliveira et al. (2005) avaliaram a bioquímica sérica de vacas Holandesas no pré e pós-parto e observaram valores para as concentrações da enzima gamaglutamiltransferase, de $13,54 \mathrm{mg} / \mathrm{dL}( \pm 4,26)$ aos 180 dias de lactação. Hoedemaker et al. (2004) avaliaram os parâmetros sanguíneos de 238 vacas e observaram valores da enzima aspartatoaminotransferase (AST) de 40,0 U/L aos 77 dias pós-parto, sendo estes resultados inferiores ao deste trabalho muito provavelmente devido ao nível de produção dos animais e o período de lactação. De acordo com Kaneko et al. (1997), os valores de fosfatase alcalina (FA) também estão dentro dos valores encontrados para bovinos, sendo de 0 a $488 \mathrm{U} / \mathrm{L}$.

\section{BIBLIOGRAFIA}

AOAC. 2000. Official Methods of Analysis. $17^{\text {th }}$ ed AOAC Int. Gaithersburg, MD.

Agrianual. 2009. Anuário da Agricultura Brasileira. FNP Consultoriae Comércio. São Paulo. pp. 462 485.

Allen, M.S. 2000. Effects of diet on short-term regulation of feed intake by lactating dairy cattle. J Dairy Sci, 83: 1598-1630.

Bernard, J.K. 1990. Effect of raw or roasted whole soybeans on digestibility of dietary nutrients
Freitas Junior et al. (2010) avaliaram as variáveis plasmáticas de vacas holandesas em meios de lactação com media de produção de leite de $26 \mathrm{~kg} /$ dia alimentadas com silagem de milho e inclusão de $16 \%$ de grão de soja cru e integral na matéria seca da dieta total e encontraram concentrações de colesterol total e HDL (316,79 mg/dLe $111,19 \mathrm{mg} / \mathrm{dL})$, Glicose $(73,42 \mathrm{mg} / \mathrm{dL})$, uréia $(42,42 \mathrm{mg} / \mathrm{dL})$ e nitrogênio uréico no soro $(19,81 \mathrm{mg} / \mathrm{dL})$, valores estes semelhantes aos encontrados no presente estudo.

\section{CONCLUSÃO}

A inclusão de níveis crescentes de grão de soja cru e integral influenciou o desempenho produtivo e as concentrações dos metabólitos sanguíneos de vacas leiteiras em lactação.

\section{AGRADECIMENTOS}

Ao Conselho Nacional de Desenvolvimento Cientifico e Tecnológico (CNPq), pela concessão da bolsa de estudo, que gerou tranqüilidade e possibilitou a dedicação intensa e exclusiva a este trabalho.

À Fundação de Amparo à Pesquisa do Estado de São Paulo - FAPESP, pela concessão de auxílio à pesquisa que possibilitou a realização deste estudo.

Ao Laboratório de Pesquisa em Bovinos de Leite (LPBL) da Faculdade de Medicina Veterinária e Zootecnia (FMVZ) da Universidade de São Paulo.

and milk production of lactating dairy cows. $J$ Dairy Sci, 73: 3231-3236.

Bremmer, D.R., Ruppert, L.D. and Clark, J.H. 1998. Effects of chain length and instauration of fatty acid mixtures infused into the abomasum of lactating dairy cows. J Dairy Sci, 81: 176-188.

Christensen, R.A., Cameron, M.R., Clark, J.H., Drackley, J.K., LyncH, J.M. and Barbano, D.M. 1994. Effects of amount of protein and ruminally protected amino acids in the diet of dairy cows 


\section{BARLETTA, RENNÓ, GANDRA, FREITAS JÚNIOR, VERDURICO, MINGOTIE VILELA}

fed supplemental fat. J Dairy Sci, 77: 1618-1629.

Deresz, F., Fernandes, A.M. e Matos, L.L. 1996. Utilização da soja-grão crua na alimentação de vacas leiteiras de alta produção. Rev Bras Zootecn, 25: 113-124.

Drackley, J.K., Klusmeyer, T.H., Trusk, A.M. and Clark, J.H. 1992. Infusion of long-chain fatty acids varying in saturation and chain length into the abomasum of lactating dairy cows. J Dairy Sci, 75: 1517-1526.

Elliott, J.P., Drackley, J.K., Schauff, D.J. and Jaster, E.H. 1993. Diets containing high oil corn and tallow for dairy cows during early lactation. $J$ Dairy Sci, 76: 775-789.

Freitas Júnior, J.E., Rennó, F.P., Silva, L.F.P., Gandra, J.R., Maturana Filho, M., Foditsch, C. e Venturlli, B.C. 2010. Parâmetros sanguíneos de vacas leiteiras suplementadas com diferentes fontes de gordura. Ciên Rural, 40: 950-956.

Gandra, J.R., Rennó, F.P., Silva, L.F.P., Freitas Júnior, J.E., Maturana Filho, M., Gandra, É.R.S., D'Angelo, L.S. and Araújo, A.P.C. 2009. Blood parameters of dairy cows fed different dietary sodic monensin levels. Rev Bras Saúde Prod Anim, 10: 115-128.

Gonzales, F.H.D. 1997. Perfil metabólico no estudo de doenças da produção em vacas leiteiras. Arq Fac Vet, UFRGS, 25: 13-33.

Hall, M.B. 1998. Making nutritional sense of nonstructural carboidrates. In: Annual Florida Ruminant Nutrition Symposium, 9. Proceedings $22^{\text {nd }}$ Annual Florida Ruminant Nutrition Symposium. Florida University. Gainsville. pp.108-121.

Hoedemaker, M., Prange, D., Zerbe, H., Frank, J., Daxenberger, A. and Meyer, H.H.D. 2004. Peripartal propylene glycol supplementation and metabolism, animal health, fertility, and production in dairy cows. J Dairy Sci, 87: 2136-2145.

Kaneko, J.J., Harvery, J.W. and Bruss, M.C. 1997. Clinical biochemistry of domestic animals. $5^{a}$ ed. Academic Press. San Diego.

McDonald, P.M., Edwards, R.A., Greenhalgh, J.F.D. and Morgan, C.A. 2002. Animal nutrition. Pearson. Harlow, UK. 693 pp.

NRC. 2001. National Research Council. Nutrient requirements of dairy cattle. $7^{a}$ ed. National
Academic Press. Washinton, D.C. 381 pp.

Oliveira, N.J.F., Melo, M.M., Lago, L.A. e Nascimento, E.F. 2005. Nascimento hemograma, bioquímica sérica e histologia da biópsia hepática de bovinos após administração de polpa cítrica. Arq Bras Med Vet Zoo, 57: 418-422.

Palmquist, D.L. 1991. Influence of source and amount of dietary fat on digestibility in lactating cows. J Dairy Sci, 74: 1354-1360.

Rennó, F.P., Freitas Júnior, J.E., Gandra, J.F.R., Barletta, R.V., Naves, A.B., Gameiro, A.H. e Verdurico, L.C. 2009. Grão de soja na alimentação de vacas leiteiras. Em: Santos, M.V., Rennó, F.P., Silva, L.F.P., Albuquerque, R. Novos desafios da pesquisa em nutrição e produção animal. Editora 5D. Pirassununga-SP. v. 1: 191-214.

SAS. 2004. Version 9.1.3. SAS Institute, Cary, NC. Schauff, D.J., Elliot, J.P., Clark, J. H. and Drackley, J.K. 1992. Effects of feeding lactating dairy cows diets containing whole soybeans and tallow. J Dairy Sci, 75: 1923-1935.

Sklan, D., Ashkenazi, R., Brun, A., Devorin, A. and Tabori, K. 1992. Fatty acids, calcium soaps of fatty acids, and cottonseeds fed to high yielding cows. J Dairy Sci, 75: 2463-2472.

Sniffen, C.J., O'Connor, J.D., Van Soest, P.J., Fox, D.G. and Russell, J.B. 1992. A net carbohydrate and protein system for evaluating cattle diets. ii. carbohydrate and protein availability. J Anim Sci, 70: 3562-3577.

Valadares Filho, S.C., Magalhães, K.A. e Rocha Júnior, V.R. 2006. Tabelas brasileiras de composição de alimentos para bovinos. UFV. Viçosa, MG. 329 pp.

Van Soest, P.J. and Mason, V.C. 1991. The influence of maillard reaction upon the nutritive value of fibrous feeds. Anim Feed Sci Tech, 32: 45-53.

Weiss, W.P., Conrad, H.R. and Pierre, N.R.S.T. 1992. A theoretically-based model for predicting total digestible nutrient values of forages and concentrates. Anim Feed Sci Tech, 39: 95-110.

Wu, Z. and Huber, J.T. 1993. Relationship between dietary fat supplementation and milk protein concentration in lactating cows: a review. Livest Prod Sci, 39: 141-155. 